Dissecting Illustrated Anatomical Books: The Visual, Material, Marketing, and Technical Shifts Affecting Anatomical Atlases in the First Half of the Nineteenth Century

\title{
Cindy Stelmackowich*
}

The publication of illustrated atlases in England and France during the first half of the nineteenth century was central to making the new and emerging medical sciences authoritative and specialized. Elite physicians increasingly sought to define themselves in contrast to the open field of non-specialist medical inquiry by producing novel illustrated textbooks that relied on visualization of the body to present their arguments. The enterprising, diverse, and abundantly illustrated atlases that emerged during this period became the primary sites for the production of authoritative knowledge in medicine. This article will outline how disciplinary knowledge, based on establishing professional authority as well as teaching medical students how to see and know the body, intersected with the practical realization of producing innovative illustrated textbooks such as the anatomical atlas.

Many historians of medical illustration have generally ignored how illustrations were offered to the public - how they were structured, packaged, circulated, read, reproduced, and sold. In fact, medical historians have preferred to examine the biographical, cultural, and aesthetic or stylistic features of individual plates or illustrations, with no commentary on how visual images were made to function as pages in books that were, ultimately, material objects. ${ }^{I}$ This article will argue that an analysis of nineteenth-century anatomical visual

* Cindy Stelmackowich specializes in the visual and material cultures of medicine. She recently finished a Postdoctoral Fellowship with the SSHRC Cluster "Situating Science" and a Research Fellowship at the New York Academy of Medicine and the Lichtenberg-Kolleg, the Göttingen Institute for Advanced Study in the Humanities \& Social Sciences in Germany.

I For a few good introductory treatments on anatomical illustrations, see Martin Kemp, "Style and Non-style in Anatomical Illustration: From Renaissance Humanism to Henry Gray," Journal of Anatomy 216, no. 2 (2010): 192-208; Deanna Petherbridge and L.J. Jordanova, The Quick and the Dead: Artists and Anatomy (Berkeley: University of California Press, 1997); Michel Sappol, Dream 
culture cannot exist apart from its material forms. I will argue that the formats, appearances, and structures of the anatomical atlas were driven as much by commercial publishing interests as by campaigns by men of science for authority over the emerging mass readership. Anatomists and publishers had to work together to ensure that ideas and representations were carefully ordered and packaged before they entered the domains of medical scholarship and consumer culture.

The early and mid-nineteenth-century anatomical publications in the holdings of the Osler Library of the History of Medicine represent a seminal and "emblematic" group of medical publications that were produced in England and France during this period. My analysis of these works will focus on the similarities and differences between these different types of notable atlases, linking them to the various shifts in nineteenth-century book illustration, printing technologies, and pedagogical interests that emerged between 1800 and I850. To these ends, I will examine the position of the atlas in specific, yet shifting, discursive conjunctures. I will argue that these shifts disciplined the visual and discursive presentation of the nineteenth-century atlas, determining their various appearances, sizes, content, as well as the amount and types of illustrated material that was included.

This essay will start with an analysis of the elaborate atlases produced at the beginning of the century, when anatomists were determined to produce iconic illustrated books that corresponded with their "discoveries" of new physiological phenomena and their extensive descriptions of morbid appearances. It will examine the features that placed the first editions of these large folio works in the rare book category as well as outline how the publishers packaged and bound the atlases to appeal, at least initially, to their wealthy and elite clients, who were rare book collectors or bibliophile doctors. It will go on to demonstrate how medicine quickly and eagerly adopted the innovations in bookbinding and illustrative technique that blossomed in the first half of the nineteenth century. These innovations were reserved for the new genres of the natural sciences such as physics, chemistry, and botany that were preoccupied with natural discovery. Market incentives in the book trade directly influenced the development of the anatomical atlas, however, resulting in changes in the size, appearance, and style of the illustrated anatomical atlas. Furthermore, commercial publishers recognized the growing need

Anatomy (Washington, D.C.: U.S. Department of Health and Human Services, National Institutes of Health, National Library of Medicine, 2006). 
to produce new types of teaching atlases for the large numbers of medical students entering into newly established European and North American academic medical schools by the I840s, resulting in more serviceable pedagogical atlases to hit the market. My analysis of the anatomical atlas will thereby examine the reasons why new conceptions of the atlas emerged as new technologies, changing publishing strategies, and academic teaching demands significantly influenced the way that medical knowledge was written, illustrated, organized, and distributed by the middle of the nineteenth century.

\section{The Early Illustrated Nineteenth-Century Anatomical Atlases: Expensive Appearances, Folio Formats, Extended Production, and Limited Circulation}

In many respects, the innovative early nineteenth-century anatomical atlases came to be one of the most expensive types of books available. My analysis will begin with a discussion on the outside appearances of the bound nineteenth-century atlases in the collection of the Osler Library of the History of Medicine before exploring how they were produced and distributed. During this period, only the wealthy collectors, physicians, and elite medical institutions could afford to purchase the individual sections or pamphlets (known as fascicles) that constituted the atlases and have them bound; it was their desires and tastes that ultimately determined the look and feel of the outside of an atlas. To meet certain standards of their gentlemanly patrons then, both publishers and purchasers, but mainly the latter, usually bound the atlases in smooth quarter-, half-, or full-leather with fine calf or sheep skin. (See fig. I.) Although a book bound with a fullleather cover was the most desirable, the great vogue in the nineteenth century for half-bound books was due to how volumes appeared on the shelves of a gentleman's library: a partially bound work resting on a bookshelf gave the appearance of a full-bound book at less cost. These leather-bound atlases were frequently decorated with ornate gold tooling, incorporated marbled endpapers, and used the latest techniques to print the highest quality of illustration possible for the period. Through the process of tooling - the impressing by hand of lettering and decoration using heated brass letters, dyes, palettes, and roll tools - atlases could have embossed, gilded, and incised elements on their leather covers and spines. (See fig. 2.) The luminous effect created by the application of continuous gold 
borders and ornamentation represented the clients' and publishers' shared appreciation of medieval illuminated manuscripts and their place in the history of the decorated book. Adding to this illuminated appearance was the gilt or marbled pattern that ran along the trimmed edges of the pages - an effect created by dipping the bound book into marble solution or gilt.

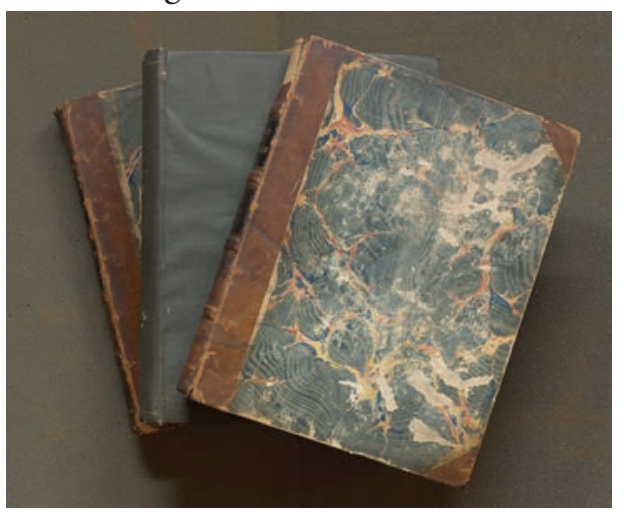

Figure I. Anatomy folios with costly bindings. Jules Cloquet, Manuel d'anatomie descriptive du corps humain : représentée en planches lithographiées, I825, vols. I-3.

(Photo: Osler Library of the History of Medicine, McGill University).

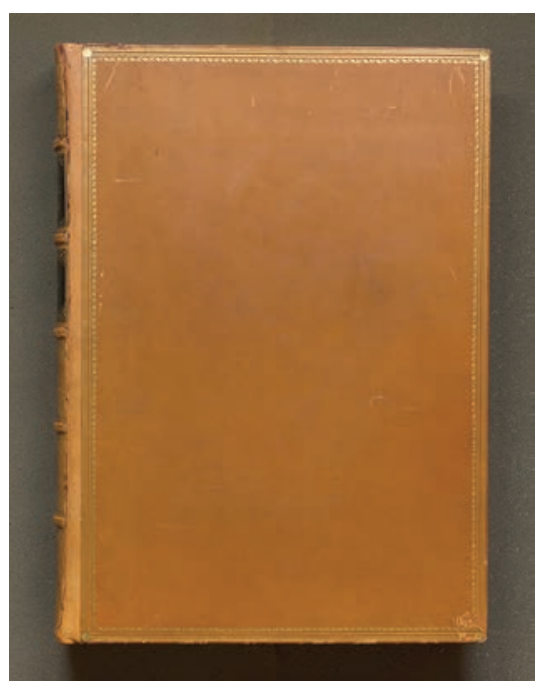

Figure 2. Gold tooling decorates the edges of the front cover. Carswell, Robert, Pathological Anatomy: Illustrations of the Elementary Forms of Disease, I838.

(Photo: Osler Library of the History of Medicine, McGill University). 
Other notable features that gave the atlas the appearance of an expensive and important rare book included the following: interleaving tissues placed in front of each plate; silk-braid bands added at the gatherings to conceal the top and bottom ends of the sewn binding; decorative raised leather bands added along the length of the spines; and even glued-in ribbons for bookmarks. Atlases were frequently printed on costly oversized folio or elephant-sized wove paper. For fine books like these, printers would use good-quality rag paper. Adding to the high costs of production were the refined illustrations that were tipped or bound in. Richly coloured illustrated plates for these atlases were printed on special paper, left blank on the reverse, and usually executed by a specialist printer. In most cases, the printing presses that produced atlases were the most prominent and prestigious presses of the period. ${ }^{2}$ Since the atlases often had a large number of pages and needed to be opened flat, they often incorporated innovative hollow backs, a binding feature that came into use in France around 1770 and in England around I8oo. This binding allowed books to open independently of the spine and was ideally suited for thick books that incorporated large numbers of illustrated plates.

Such use of fine and costly materials meant that the manufacturing of a bound atlas was clearly labour intensive. A large number of skilful labourers carried out repetitive tasks to execute the ornate effects for the elaborate bound atlas. At the beginning of the nineteenth century, the first editions were printed and produced in small shops by artisans. By the I830s, printing was dominated by a few large firms working on an industrial scale in the large cities. The effect of these large firms meant that, as the century progressed, an extensive division of cheap labour was created. These new firms employed hundreds of workers who worked with extraordinary speed, because payment was by piecework. It was not until the I840s that book printing reaped the benefits of the steam technology introduced for

2 Two significant examples in the Osler Library of the History of Medicine include the atlases of Jean-Baptiste Marc Bourgery and Jules Cloquet. Bourgery's volumes, which extended over twenty years, were printed by a variety of printers, depending on the volumes and the years. The primary printer employed was the printing workshop of Rose-Joseph Lemercier, the top address for lithography in Paris, with around a hundred presses in I838. Cloquet's atlas was printed at the press of Charles de Lasteyrie and Godefroy Engelmann, who pioneered lithographic printing in France. The elite Lasteyrie firm was "Lithographer of the King." 
newspaper publication earlier in the century. The atlases produced in the first few decades of the nineteenth century were often either produced entirely by hand, or were a hybrid product - the result of tedious manual labour as well as machines such as the steam press (a topic discussed in the second section of the essay).

Most tasks related to the production of the early nineteenthcentury atlases were completed by hand, including the layout, proofing, binding, sewing, and decorating. ${ }^{3}$ All the atlases from this period were produced by letterpress hand printing. This meant that a compositor would choose the font and size and set individual lines of type into a composing stick and then adjust the word and line spacing by hand. Each page needed to be hand blocked this way to get it ready for printing. The plethora of anatomical terms and descriptions, unfamiliar to the compositors and to the printer's proofreaders, would obviously have required extra time and careful editing. Once printed and at the bindery, the sets of sheets for each copy needed to be folded by hand. The illustrated pages, printed elsewhere, would need to be cut down to size from larger sheets and would be put into the proper order at this stage. All ordered sheets were sent to collators, who checked for correct order and folding. If the atlas included large, extended fold-outs, they too were made to fit, all by hand, in the correct position. After pressing, the sheets were then passed to the sewer. In the large firms, the labour of folding, collating, and sewing was carried out entirely by women. Working by hand, women carried out the necessary repetitive tasks that required a high degree of accuracy: sheets aligned, pages in exact order. Because bookbinding involved sewing and other activities associated with the domestic sphere, middle-class employers regarded it as a form of labour appropriate for women. ${ }^{4}$ The heavier tasks of pressing and steam-printing the pages, as well as all the jobs associated with machines, were undertaken by men at the printing and binding factories. All work had to be carried out quickly and efficiently, although payment for these tasks was extremely low.

3 See the chapters entitled "A Day at a Printing-Office" and "A Day at a Bookbinder's," in George Dodd's Days at the Factories; or, The Manufacturing Industry of Machines and Processes (London: Charles Knight \& Co., I843), 326-86.

4 Ibid. See also the chapter related to bookbinding, especially 367-7I. The author notes: "It is a fortunate circumstance, considering the very limited number of employments for females in this country, that there are several departments of bookbinding within the scope of their ability." 
Anatomical atlases dating from the early nineteenth century were not initially offered to the public as ornately bound volumes. Rather, information that constituted the atlas was initially published in fascicles or as pamphlets that were delivered to the client over the course of many years. It was not uncommon for it to take many years, even a decade or more, to produce and publish an entire atlas containing original content and illustrations. These projects were clearly huge undertakings for everyone involved, not only for the anatomists, but also for the artists, publishers, and printers. Subscribers to the fascicles would receive each installment in the mail immediately after printing. For example, each of the ten installments issued over the course of four years ( $1799-1803)$ in Matthew Baillie's first-edition illustrated atlas included approximately ten pages and eight plates, with up to five or six figures on each illustrated page. ${ }^{5}$ It took ten years to publish Jules Germain Cloquet's atlas in extenso: fifty-one parts, constituting five volumes, were issued between I82I and I83r. ${ }^{6}$ In the case of Jean Cruveilhier's atlas (I829-42), twenty fascicles were produced over thirteen years. ${ }^{7}$ During these years, Cruveilhier became the first to hold the chair of pathological anatomy at the Faculty of Medicine at the Paris Academy in I836. This was a major appointment in the history of European medicine, as it was the very first position of its kind to be established anywhere. Physicians worldwide would have paid close attention to the research findings of this "intellectual genius" who was described as the "great man of science" associated with the Paris School. ${ }^{8}$ In fact, it was in his atlas that Cruveilhier first described multiple sclerosis and what is termed "Cruveilhier's palsy." Hypertrophic pyloric stenosis and ulceration of the stomach due to hyperacidity were also described for the first time in this atlas. Issuing information as soon as it was printed via fascicle meant that the audiences for this information, which included an educated male audience with an occupational interest in the medical

5 Matthew Baillie, A Series of Engravings, Accompanied With Explanations, Which are Intended to Illustrate the Morbid Anatomy of Some of the Most Important Parts of the Human Body Fasciculus [I-X] (London: J. Johnson, I799-I803), preface.

6 Jules Cloquet, Anatomie de l'homme, ou description et figures lithographiées de toutes les parties du corps humain (Paris: De Lasteyrie, I82I-3I).

7 Jean Cruveilhier, Anatomie pathologique du corps humain: ou, Descriptions, avec figures lithographiées et coloriées, des diverses altérations morbides dont le corps humain est susceptible (Paris: Baillière, I829-42).

8 See Samuel Cooper, A Dictionary of Practical Surgery: Comprehending All the Most Interesting Improvements, from the Earliest Times Down to the Present Period (London: Longman, Orme \& Co, et al., I838), I399-I405. 
sciences or an elite audience with an interest in rare books, would have access to original information relatively quickly and would not have to wait until the end of the very lengthy process associated with producing an illustrated atlas. How these elite groups initially received and responded to a continuing subscription to installments would obviously have been very different from other readers' interaction with the atlas as a bound set of volumes.

Packaging and disseminating information through fascicles was one of the new modes of publication created by an emergent print and graphic culture at the beginning of the nineteenth century. These new trends were important for both the natural sciences such as botany and chemistry as well as the medical sciences. The fascicle mode was reserved primarily for the new notions of progress, natural discovery, and useful knowledge. This type of literature included the new kinds of encyclopedic works and scientific genres concerned with propagating knowledge. ${ }^{9}$ A notable example, and one that surely had an influence on the anatomical atlas, was the Description de l'Égypte - the massive compendium that Napoleon ordered to document his expedition to Egypt from 1798 to I80I. ${ }^{\text {IO }}$ This unprecedented scholarly achievement published via fascicles in folio form with elephant-sized plates between I809 and I 828 offered scientific descriptions of ancient and modern Egypt and involved the collaborative work of about I60 scholars and scientists, known popularly as the savants. The first edition of this profusely illustrated work was composed of ten volumes of text and thirteen volumes of illustrations consisting of 894 plates made from three thousand drawings. ${ }^{\text {II }}$

9 On the history of encyclopedias, see Marina Frasca-Spada and Nick Jardine, eds., Books and the Sciences in History (Cambridge: Cambridge University Press, 2000). See also Adrian Johns, The Nature of the Book: Print and Knowledge in the Making (Chicago: University of Chicago Press, 1998); and Richard Altick, The English Common Reader: A Social History of the Mass Reading Public, I800-1900 (1957; repr., Columbus: Ohio State University Press, 1998).

Io The full title of the work is Description de l'Égypte, ou Recueil des observations et des recherches qui ont été faites en Égypte pendant l'expédition de l'armée française (Paris: De L'Imprimerie Impériale, I809-28). The second edition, not dedicated to Napoleon but to Louis XVII, was published by Charles Louis Fleury Panckoucke starting in 1820 . In this version, the text was expanded into more volumes (thirty-seven in total) and made less costly because it was printed in a smaller format, in black and white.

II It is believed that about two thousand artists and technicians worked on producing the plates for Description de l'Égypte, including four hundred engravers. See Lisa Small's "Napoleon on the Nile," in Napoleon on the Nile: Soldiers, Artists, and the Rediscovery of Egypt (New York: Dahesh Museum of Art, 2006): 7-42. 
The fact that the anatomical atlas was produced and distributed in a similar format to this type of encyclopedic work instantly designated it as a commanding publication. Honourable and noble tasks were expected from publications that issued information via fascicle; they needed to satisfy the quest for knowledge and personal intellectual growth. As such, they were obviously designated for a very specific community that had an intense interest in receiving the latest news as it developed within the various branches of the natural and medical sciences. According to historian Richard Yeo, the developments in the sciences at the beginning of the nineteenth century were linked with a strong concern about the boundaries between them. He notes that, especially in the types of treatises devoted to the new sciences of geology and physiology, for instance, "the integrity of each subject as a discipline with its own intellectual domain" was paramount. ${ }^{12}$ It was thereby vitally important that the medical profession and elite physicians at the turn of the century distinguished themselves from the open field of non-specialist medical inquiry and healing sects. Advertisements from "quacks" constituted a large body of information during this period. ${ }^{\mathrm{I3}}$ The production of novel illustrated textbooks that disseminated arguments quickly and through systematizing formats already endorsed by the scientific elite was integral to their professional status. To these ends, the anatomical atlas was to become instrumental in supporting the systematic codification and prestige on which nineteenth-century medical knowledge was to depend.

The most popular illustrative technique used in medical books during the first three decades was engraving (on steel and copper plate), although there was also evidence of etching and wood engraving. Initially, illustrations at the turn of the century were largely either in black and white, or, occasionally, hand water-coloured. In Matthew Baillie's 1799-1803 groundbreaking atlas, A Series of Engravings, Accompanied With Explanations, Which are Intended to Illustrate the Morbid Anatomy of Some of the Most Important Parts

Information related to the scientists can be found in Nina Burleigh's Mirage: Napoleon's Scientists and the Unveiling of Egypt (New York: Harper Perennial, 2008).

I2 Richard Yeo, "Reading Encyclopedias: Science and the Organization of Knowledge in British Dictionaries of Arts and Sciences, I730-I850," ISIS 82 (I99I): 24-49.

I3 For an interesting article on quackery see K. Codell Carter's "The Concept of Quackery in Early Nineteenth Century British Medical Periodicals," Journal of Medical Humanities I4, no. 2 (June 1993): 89-97. 
of the Human Body; Divided Into Ten Fasciculi, the inclusion of black-and-white illustrations of morbid parts was considered an experiment on multiple levels. ${ }^{14}$ Baillie's text was produced at a time when profound and unique pathological investigations were taking place across Europe. Not only have a number of medical historians considered Baillie's work to be one of the initial publications within medicine to include morbid anatomy parts but they have also noted that Baillie's text changed the way pathology, and more specifically the iconography of pathology, were addressed. ${ }^{15}$ Based on a series of watercolour drawings by William Cliff, the former assistant and conservator of the infamous William Hunter Museum, ${ }^{16}$ engravings for the publication were produced in London through a relief-based process on quarto-sized pages. Clearly Baillie and Cliff could draw not only from their own collections, but from the vast preserved specimens and wet and dry preparations assembled by Baillie's uncles, William and the later John Hunter. Like most illustrations from these early pathological atlases, the images of morbid parts relied on stippling effects, directional lines or cross-hatching techniques, and stark contrasts to create modelling effects. These images were much smaller than life sized, and pages of textual descriptions tended to outweigh the number of illustrations - a direct result of the high expense, at the time, of producing and printing illustrations.

Throughout the initial decades of the nineteenth century, physicians tried to persuade their peers to avoid producing the dreary non-illustrated and didactic tracts of earlier times and to consider effectively linking their ideas to the emerging techniques in book

I4 Baillie noted in the preface that, because no anatomical works focusing exclusively on illustrating morbid change had been published to that point, he "ventured to undertake such a work; but [I] only propose to proceed in a little way, till the opinion of the Public with regard to it is collected. If that shall be favorable, it will encourage me to advance with earnest diligence."

is For scholarship on Baillie and the early history of pathology, see Alvin E. Rodin, The Influence of Matthew Baillie's Morbid Anatomy (Springfield, IL: Charles C. Thomas, 1973); Andrew Cunningham, The Anatomist Anatomis'd. An Experimental Discipline in Enlightenment Europe (Farnham: Ashgate, 2010); George J. Cunningham, The History of British Pathology (Bristol: White Tree Books, I992).

I6 See W.F. Bynum and Roy Porter, William Hunter and the Eighteenth-Century Medical World (Cambridge: Cambridge University Press, 1985) as well as Hunterian Museum, London, Descriptive Catalogue of the Pathological Series in the Hunterian Museum of the Royal College of Surgeons of England, 2 vols. (Edinburgh: E. \& S. Livingstone, 1966-72). 
illustration. Although Baillie noted at the start of the project that he was unsure about producing an exclusively illustrated work, he believed his illustrated atlas would "be an important desideratum in Anatomy, to comprehend in one work, upon some regular plan, engravings of the chief morbid changes of structure in the most essential parts of the human body, which are capable of this kind of illustration." ${ }^{\prime 7}$ The medical community, including members of elite circles in Paris, London, Edinburgh, Amsterdam, and Berlin, responded quickly and favourably to Baillie's initiatives. Charles Bell continued to argue in favour of the value of illustrations in anatomical education in the preface of his I8OI atlas, remarking that the incorporation of visual images would ease the onerous task of learning anatomy: "The plates prepare us better for undertaking any surgical operation than that of bare description, however accurate, however simple, or however constantly the true practical inferences may be kept in view. It is upon the eye that the impression must be made, which is to enable us, in looking upon a limb, to mark the course of the Arteries; drawings are a kind of notes, too, more easily consulted, and bring to the mind, in a more lively manner, all that was associated in our first studies." ${ }^{18}$ Experimentation with the various kinds of modern printing technologies on offer was not only encouraged, but became a critical means for both physicians and publishers to differentiate their current-day atlases from prior anatomical treatises focused only on text, charts, and tables. In fact, the inclusion of any type of visual content in a treatise would have been considered a major draw, especially if the plates represented an emergent illustrative technique.

Increasingly, illustrations became a common feature of elite physicians' treatises in the following decades. Not only did these physicians maintain that their ideas were greatly facilitated by the introduction of engravings, but publishers responded favourably as well, surely aware that illustrations would be received positively by a growing medical community - especially those with little or no access to a reliable and consistent supply of cadavers - with a pressing interest in anatomy and images of dissection. During this period of transition away from non-illustrated texts, when the

${ }_{17}$ Mathew Baillie, A Series of Engravings, preface.

I8 Charles Bell, Engravings of the Arteries, Illustrating the Second Volume of the Anatomy of the Human Body by J. Bell (London: Longman and Rees, I80I), preface. 
visual was gaining acceptance as an important epistemological site for medical knowledge, both the size and number of illustrations included in the atlases increased. ${ }^{19}$ Furthermore, various kinds of colour printing were introduced. Richard Bright, whose I827-3I atlas featured brightly coloured stippled engravings, maintained that the effects of using colour resulted in images that were more direct, potent, and thus valued: "the changes of structure will be illustrated by color engravings, so highly finished as to present faithful pictures of the morbid appearances." ${ }^{20}$ The addition of coloured images, it was believed, rendered descriptions more intelligible and more vivid. So it was only a short time after Baillie began his atlas that illustration began to be used as a vehicle for the transmission of knowledge for the young profession. ${ }^{2 \mathrm{I}}$

Starting in the late I820s, planographic processes such as lithography began to be employed and soon dominated medical book illustration. Lithography differed significantly from processes used earlier in that the plate is neither carved in relief nor incised; the illustration to be printed is drawn directly onto a flat piece of stone with a specially prepared greasy chalk pencil. ${ }^{22}$ The first lithographic atlas was Cloquet's folio-sized atlas. It was published between I82I and I83I by Chez Bechet, printed in the two first lithographic ateliers of Paris (established by Charles de Lasteyrie and Godefroy Engelmann),

I9 The visual was a highly charged and evolving arena within medical science during this period, especially within medical education and research. Examinations of cadavers, specimens, bones, as well as the new and older types of anatomical models and sculptures were actively incorporated into anatomical teaching in private schools and laboratories as well as academic medical institutions. For recent studies on the historical role of dissection, anatomical preparations, and models in medical teaching, see R. Knoeff and R. Zwijnenberg, eds., The Fate of Anatomical Collections (Farnham: Ashgate, 2015); and Anna Maerker, Model Experts: Wax Anatomies and Enlightenment in Florence and Vienna, I775-I8I5 (Manchester: Manchester University Press, 20II).

20 Richard Bright, Reports of Medical Cases, Selected with a View of Illustrating the Symptoms and Cure of Diseases by a Reference to Morbid Anatomy (London: Richard Taylor for Longman, Rees, Orme, Brown and Green, 1827-31), preface.

2I An analysis focused on the visual languages of anatomical illustrations can be found in my article, "Bodies of Knowledge: The Nineteenth-Century Anatomical Atlas in the Spaces of Art and Science," RACAR (University Art Association of Canada Journal) 33, no. I-2 (Winter 2008): 75-86.

22 William C. Maxwell, Printmaking: A Beginning Handbook (Englewood Cliffs, NJ: Prentice-Hall, 1977), 203-66. 
and contained three hundred plates. ${ }^{23}$ Soon after Lasteyrie also started to publish Antommarchi's Planches anatomiques du corps humain, the pirated lithograph edition of Mascagni's Anatomia universa. ${ }^{24}$ This early example of a lithographic atlas, using double-elephant oversized plates, represented the largest work in terms of size issued by Lasteyrie's lithographic press. The full-sized illustrations from this work measure 36 inches high by $24^{1 / 2}$ inches wide. Lithography was highly valued by illustrators, authors, and publishers alike due to the new kinds of realistic effects lithographic processes could produce. The unprecedented hyper-naturalism that illustrators claimed they could achieve with the medium, combined with the fact that lithographs proceeded much more quickly than the process of engraving, made lithography the preferred printing and pedagogical technology by the i830s.

The lithographic atlases that preceded Cloquet's and Antommarchi's impressive atlases contained a very large number of original illustrations. The many figures in each atlas often equalled, and sometimes outweighed, the textual descriptions and details of the anatomist's clinical observations and case history notes. Presented in large formats, illustrations from this period were considered to be "Life-sized." (See fig. 3 and 4 for examples of how the traditional large double-paged spreads appeared in anatomical atlases.) Referred to as folio-, imperial folio-, or elephant-sized atlases, these multiplevolume sets often claimed to cover the "whole of anatomy" or the "entire elementary forms of disease." They were often issued over many years. The initial bound volumes of Bourgery's atlas, for example, were produced in large folio format, and comprised 2,I08 pages with 725 plates, representing a total of 3,750 figures. ${ }^{25}$ In a few instances, large fold-outs were included in Bourgery's that were to be unfolded vertically or horizontally in order to reveal one spatially legible human body. (See fig. 5 for a spectacular example of a four-sheet folio illustration inserted at the back of volume three

23 Cloquet, Anatomie de l'homme.

24 Originally issued in fifteen parts, I823-26; a full set consisted of forty-eight numbered plates and forty-eight numbered outline plates with some partially hand coloured. Francesco Antommarchi, Planches anatomiques du corps humain exécutées d'après les dimensions naturelles (Paris: Imprimerie Lithographique de C. Lasteyrie, $1823-26$.

25 Jean-Baptiste Marc Bourgery, Traité complet de l'anatomie de l'homme comprenant la médecine opératoire: avec planches lithographiées, 8 vols. (Paris: C.A. Delaunay, I83I-54). 


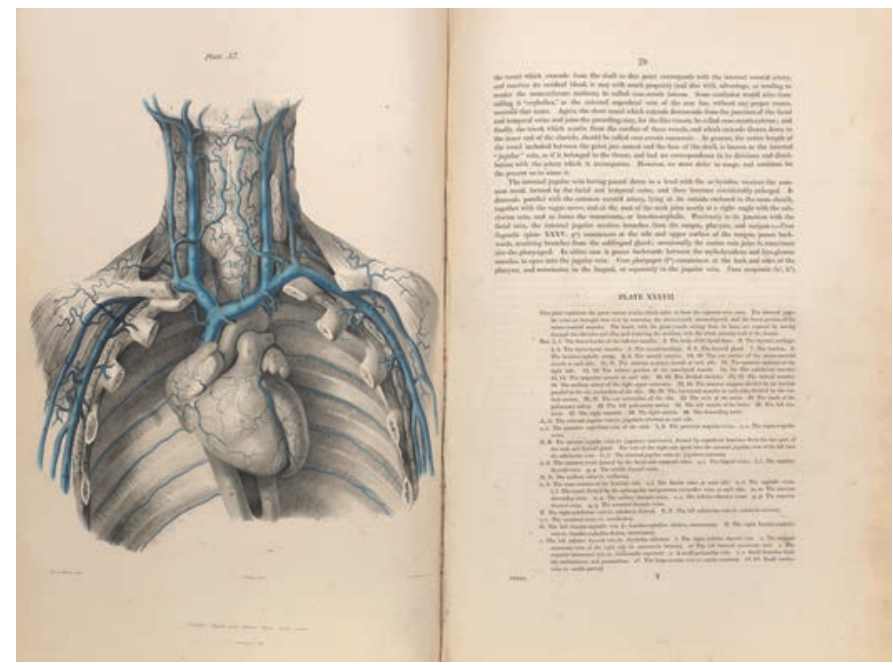

Figure 3. Jones Quain, 1796-1865, A Series of Anatomical Plates: with References and Physiological Comments Illustrating the Structure of the Different Parts of the Human Body / edited by Jones Quain and Erasmus Wilson, 1842, pl. 37. Coloured lithograph. (Photo: Osler Library of the History of Medicine, McGill University).

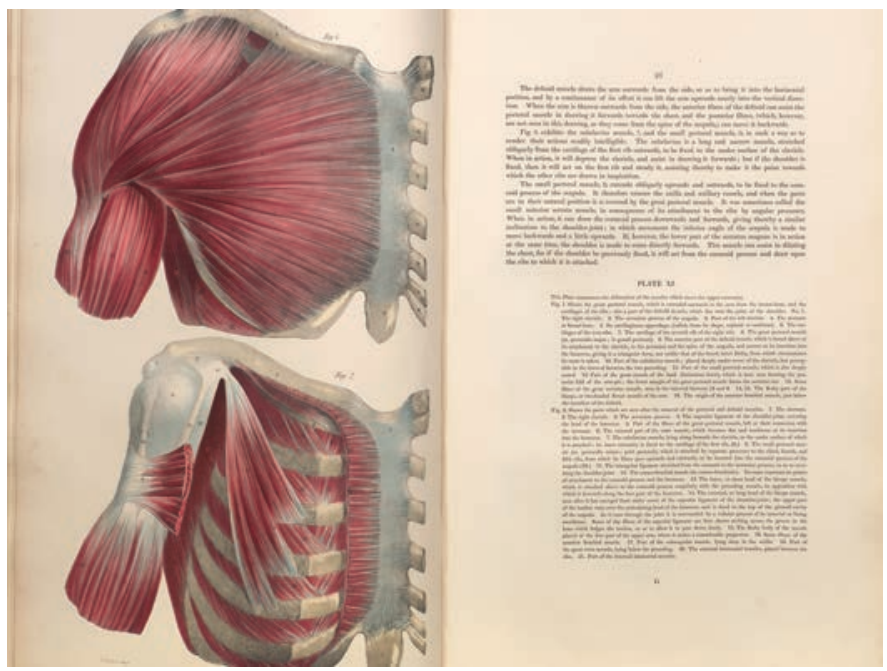

Figure 4. Jones Quain, 1796-1865, A Series of Anatomical Plates: with References and Physiological Comments Illustrating the Structure of the Different Parts of the Human Body / edited by Jones Quain and Erasmus Wilson, I842, pl. II. Coloured lithograph. (Photo: Osler Library of the History of Medicine, McGill University). 


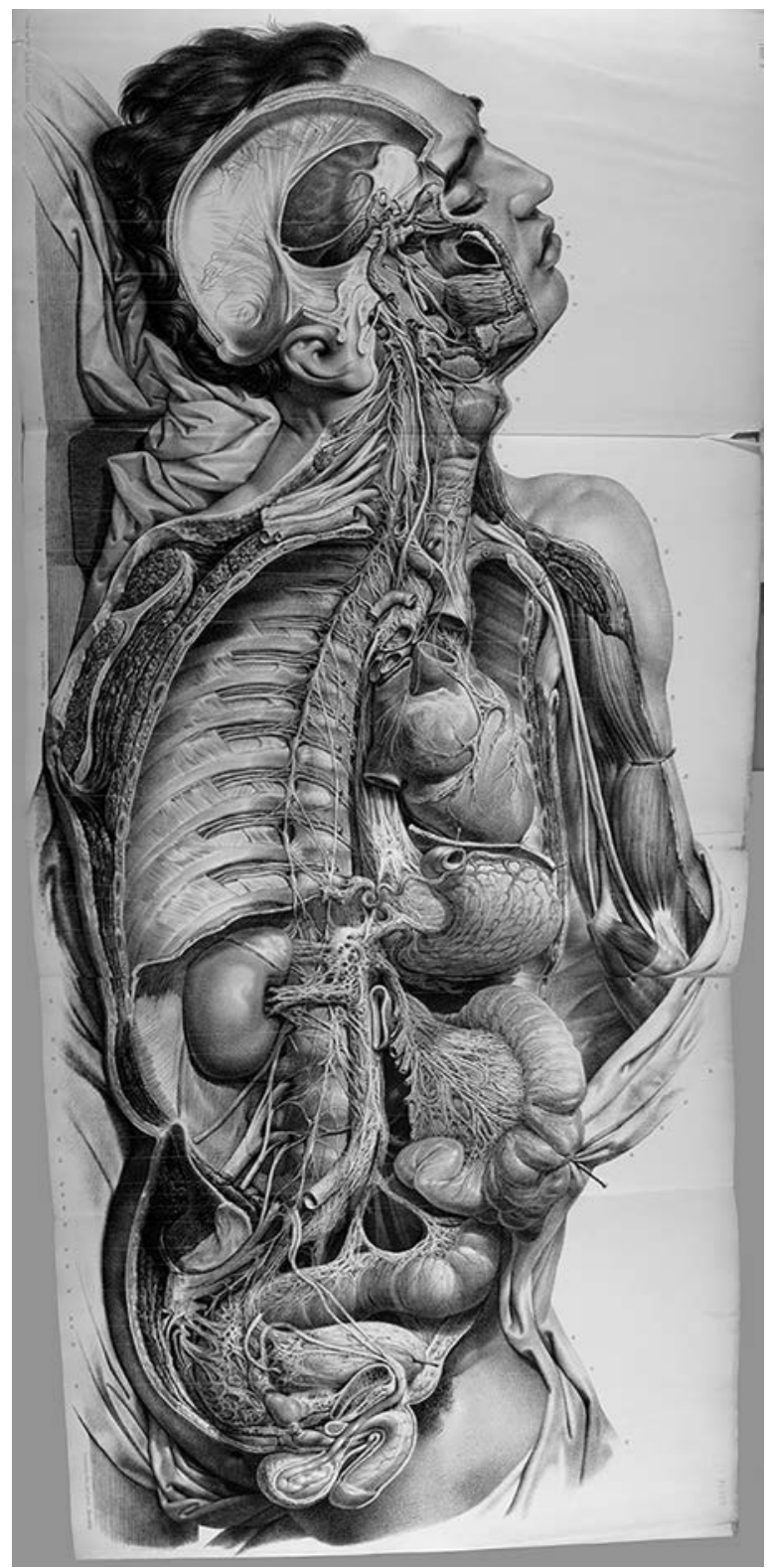

Figure 5. Jean Marc Bourgery, Traité complet de l'anatomie de l'homme, I83I-53, v. 3, pl. Ioo. Foldout lithograph by Nicolas Henri Jacob on wove paper. (Photo: Osler Library of the History of Medicine, McGill University). 
of Bourgery's atlas that, once unfolded, discloses an exhaustively detailed image that measures ninety-eight centimeters.) Between I83I and I844, seventy sixteen-page pamphlets of Bourgery's work were delivered to subscribers, each with eight pages of plates and eight pages of descriptive text and legends. The initial eight volumes were published starting in I831, and were finally completed in 1854, five years after his death. Beginning at the same time as the periodical publication, the atlas was also bound into more permanent volumes, and three versions were on offer: two in black and white - one on regular paper and the other on "China paper" - and a special version incorporating hand-coloured lithographs, also on "China paper." The initial price for a black-and-white bound copy was unaffordable for a medical student at eight hundred francs, considerable for the time; the price for a colour copy was twice that.

In addition to profusely illustrated general or surgical atlases, anatomists were determined to produce illustrated works of morbid anatomy that corresponded with the elaborate descriptions of morbid appearances that were appearing in the medical field. Still lamenting the lack of illustrated medical texts, Robert Carswell in I834 stated that he produced his illustrated pathological atlas as a result of " $t]$ he great difficulty, and frequently the impossibility, of comprehending even the best descriptions of the physical or anatomical characters of diseases, without the aid of colored delineations." ${ }^{26}$ Carswell believed illustrations could accurately render real bodies and disease, and could serve as documentation of pathological conditions. In this respect, illustrated pathological atlases were to show what diseased bodies would look like in order to acquaint anatomists and their students with the most common and the rarest maladies they might encounter. Ultimately, they were to aid in physicians' calibration of what the profession was determining to be "abnormal" versus "normal."

Focused exclusively on post-mortem appearances, a number of significant illustrated pathological atlases were published in the I830s. In Jean Cruveilhier's pathological atlas (I829-35), thirty delicately hand-coloured lithographic plates of various diseased membranes and organs were included as "proof" of his diligent clinical and post-mortem observations. ${ }^{27}$ Aside from specimens

26 Robert Carswell, Pathological Anatomy. Illustrations of the Elementary Forms of Disease (London: Longman, Orme, Brown, Green and Longman, 1838), preface.

27 See Jean Cruveilhier, Anatomie pathologique du corps humain, ou Descriptions, avec figures lithographiées et coloriées, des diverses altérations morbides dont le corps humain est susceptible, vol. 2 (Paris: Baillière, I829-42). This atlas contains 
showing common afflictions, the atlas also showcased his collection of prized morbid specimens. In 1832, Carswell displayed forty-eight hand-coloured lithographic plates in his folio atlas, the product of years spent in France building up a pictorial teaching library of morbid anatomy cases directly from dissected bodies. (See fig. 6.) Each of these atlases was swiftly recognized, and they remained esteemed throughout the century. At the end of the century, one reviewer noted of Carswell's atlas that "these illustrations have, for artistic matter and for fidelity, never been surpassed, while the matter represents the highest point which the science of morbid anatomy had reached before the introduction of the microscope." 28 Cruveilhier's atlas was also acclaimed as "one of the most beautifully illustrated books on pathology." ${ }^{29}$ What drew praise, then and now, for these atlases was that their drawings of excised morbid parts were not only meticulously rendered in unprecedented detail, but they were hand-coloured with bright paints, often in combination with contrasting or complementary washes. This experimentation in the use of vibrant washes of colour to create lines, shapes, and volumes yielded interesting textural effects and marbleized patterns. Rather than the simple directional lines and cross-hatching techniques found in pathological engravings at the beginning of the century, such as those found in Baillie's illustrated atlas, these were overly saturated and colourful figures made into highly detailed and vivid icons.

The extended periods of time and energy dedicated to these mammoth projects demonstrate the importance of the new kinds of illustrated textbooks and their results. They were not only meant to institute the principles related to modern medicine; the authors of these atlases instantly became the heroes of science. It is not surprising, then, that in the preface to his atlas Bourgery described himself as both honourable and self-disciplined, stating that "aucun sacrifice ne nous cồtera pour terminer honorablement l'immense travail que nous avons entrepris." ${ }^{30}$ Presenting himself as a self-disciplined and heroic scientist possessing the ability to strive for truth, Bourgery validated the credibility of his work and demarcated the atlas as being an

more than two hundred copper plates of gross pathology as well as coloured lithographs, done by the anatomical illustrator, Antoine Chazal.

28 This comment appeared in the entry for Sir Robert Carswell in the Dictionary of National Biography IX (I887): I9I.

29 John L. Thornton and Carole Reeves, Medical Book Illustrations: A Short History (Cambridge and New York: Oleander Press, 1983), I6I.

30 Bourgery, Traité complet de l'anatomie de l'homme, vol. 5, 7. 


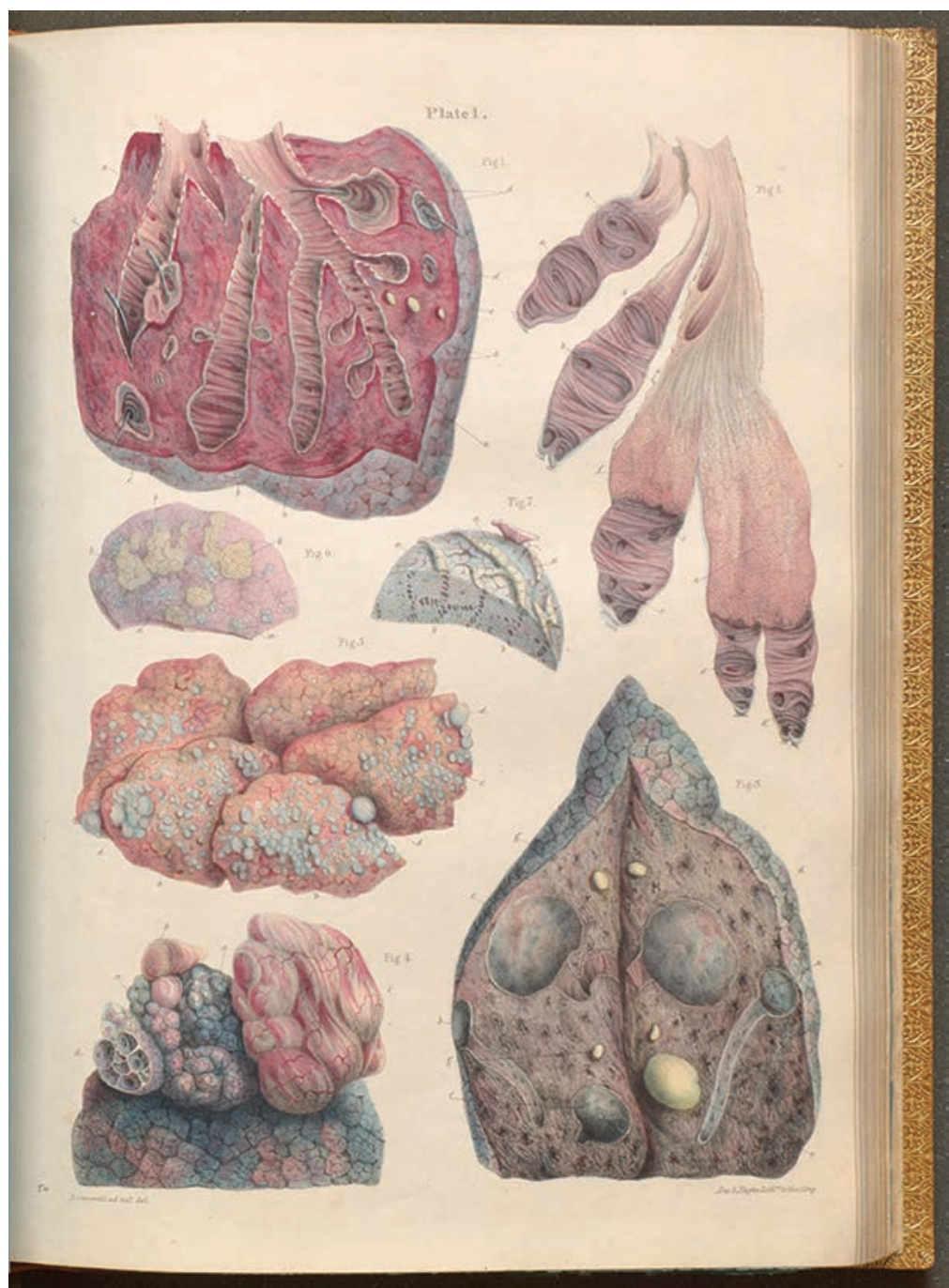

Figure 6. Robert Carswell, Pathological Anatomy: Illustrations of the Elementary Forms of Disease, 1838, pl. I. Coloured lithograph. (Photo: Osler Library of the History of Medicine, McGill University).

original work in science. This notion of the heroic anatomist who had the rigour and self-discipline to produce original scientific work and faithfully carry it every step to publication has been emblematic throughout the history of Western anatomy (e.g., Vesalius, Hunter, 
and Albinus). Publishers in the nineteenth century, perhaps more prosaically, continued to encourage a heroic role for the man of knowledge because familiar names sold books.

The publishers of anatomical atlases during the first half of the nineteenth century tended to be the leading specialist publishers in England and France. Physicians were well aware that publishing an illustrated atlas by an experienced publisher who was reputable in medical circles and had connections to a cadre of expert engravers and lithographers was vital to the atlas's success. A prominent publisher would guarantee an author a certain amount of profit and prestige, as well as find ways to advertise his or her texts. Anatomists and publishers had to work together to ensure that ideas and visual representations were carefully ordered and packaged before they entered into the domain of medical consumer culture. The format, appearance, and structure of the anatomical atlas were thereby driven as much by commercial publishing interests as by campaigns by men of science for authority over the emerging readership interested in the latest medical discourse.

In London, a variety of firms published medical and scientific treatises at the beginning of the nineteenth century. For instance, in the I834 trade publication, The London Catalogue of Books, with Their Sizes, Prices and Publishers, approximately 1,200 books published in London from I8I4 to I834 fell under the category of "Medicine, Surgery, Physiology and Chemistry." ${ }^{\mathrm{I}}$ This bookseller's catalogue shows not only the incredible number of publications in the medical field produced during this period, but also the dozens of publishers of medical books in London. Some medical publishers were quite popular and instrumental, like Churchill's, whose firm was a favourite for London medical men. John Churchill, the founder, opened his publishing firm in London in 1728 with a list of medical books dating back to I688. The success of businesses like Churchill's was due to their focus on providing professors with limited editions as soon as they were published in fascicles, as well as publishing lectures by leading anatomists of the period. A number of these specialist firms began publishing specialized medical journals and reviews to ensure that their firm both remained in the medical headlines and was connected to the most current ideas in the field. In most cases,

31 Richard Bent, The London Catalogue of Books, with their Sizes, Prices, and Publishers. Containing the Books Published in London, and Those Altered in Size or Price, since the Year I8I4 to December I834 (London: Richard Bent, I835). 
publishers ventured into the journal trade probably aware that it would result in a loss. Nonetheless, in I838, Churchill became the publisher of the prestigious quarterly, British and Foreign Medical Review, and from 1842 to 1847 it issued one of the most important medical journals of the period (and of today), The Lancet. The Lancet appeared weekly and reported on lectures, surgical operations, and medical news in general. Most of the atlases published during this period were reviewed in this journal, which claimed to cater to the needs of medical men from the second decade onward; book reviewing had become a major literary industry. Unsurprisingly, the reviews of Churchill's atlases in the Lancet and the British and Foreign Medical Review were highly positive.

Longman was also a major publishing company of medical textbooks during the period. Founded in London in 1724 by Thomas Longman, the firm has the distinction of being the oldest commercial publisher in the English language. By the turn of the nineteenth century, Longman partnered with a number of associates (the name of the firm changed at this time to Longman, Hurst, Rees, Orme, Brown $\&$ Green) and purchased the copyright of the most notable works in the country. ${ }^{32}$ Longman's sons continued to work in the successful business and were responsible for editing many illustrated volumes, such as the New Testament (one of the first illustrated editions) Macaulay's Lays of Ancient Rome, and the first two volumes of his History of England, which in a few years set sales records. Longman's success working with top illustrators and publishing a number of significant and innovative large elephant folios in the natural sciences may have led to eminent physicians' preference for this publisher when looking to publish an illustrated anatomical work.

Jean-Baptiste Baillière, whose firm was known as Chez J.B. Baillière, dominated medical and scientific book publishing in Paris. In 1827 Chez J.B. Baillière was designated publisher to the Académie royale de médecine and held the post until December I87I. In addition to medical treatises, the firm published important specialized literature for the medical field. It published the Annales and the Bulletin de l'Académie as well as specialized medical journals and reviews, including the Archives générales de médecine (1823-56), the Journal de médecine (1828-30), the Annales d'hygiène publique et

32 Such as Lindley Murray's English Grammar (which had an annual sale of about fifty thousand copies), Southey's Joan of Arc, Wordsworth's Lyrical Ballads, and the Edinburgh Review, founded in I8O2. 
de médecine légale (1829-56), and the Journal de médecine, chirurgie (1833-56). Besides the publisher's connection to the Académie royale de médecine, the most notable physicians probably worked with Chez J.B. Baillière because of the firm's reputation for reliability, rapid turnaround, rigorous corrections, quality suppliers (paper makers, printers, binders, engravers), and close attention to the execution of drawings and illustrations. ${ }^{33}$ Most importantly, however, J.B. Baillière was also a bookseller who took an early interest in aggressively pursuing profitable markets outside of Paris. After planning to translate French medical texts and distribute them abroad himself, Baillière decided his company had to be international. This meant that while the Paris School was establishing its reputation as a mecca for students to learn new medical knowledge, Chez J.B. Baillière began to distribute the works of the eminent professors from the Paris School outside of France. Chez J.B. Baillière's enterprising publishing initiatives were thereby fundamental in securing and propagating the international prestige on which French nineteenth-century medical knowledge was to depend. By the I830s, the firm quickly and easily expanded its Paris offices to a successful London branch. Furthermore, Baillière established a very dense network of correspondents that enabled him to do away with agents; he sought and secured contacts in other countries to conduct promotions, sales, and translations. The firm's international reputation was firmly established in its new title after I830: "CHEZ J.B. BAILLIËRE" in large capitals was followed by "Librairie de l'Académie Royale de Médecine, du Collège Royal des Chirurgiens et de la Société Royale de Londres. Et Chez les Principaux Librairies de la France et de L'étranger."

It is hard to be specific about patterns of distribution for atlases and medical textbooks produced between I80o and I840, or for any book of the period, as most of the relevant records have been destroyed. What does seem clear is that initial copies of fascicles were offered first to subscribers who had paid in advance of printing. In some instances, the identity of subscribers was known. For example, following the title page of Cruveilhier's atlas was a page that listed in long columns the names of the individuals and institutions that had agreed to purchase the entire set of fascicles. (See fig. 7.) Approximately two hundred names were listed on Cruveilhier's liste des souscripteurs, a weighty number for an anatomical atlas during this period. The names

33 J.L. Thornton and Christian Regnier, "Jean-Baptiste Baillière (I797-I885)," in Medicographia 27, no. I (2005): 87-96. 


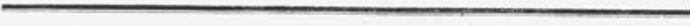

LISTE DES SOUSCRIPTEURS.(1)

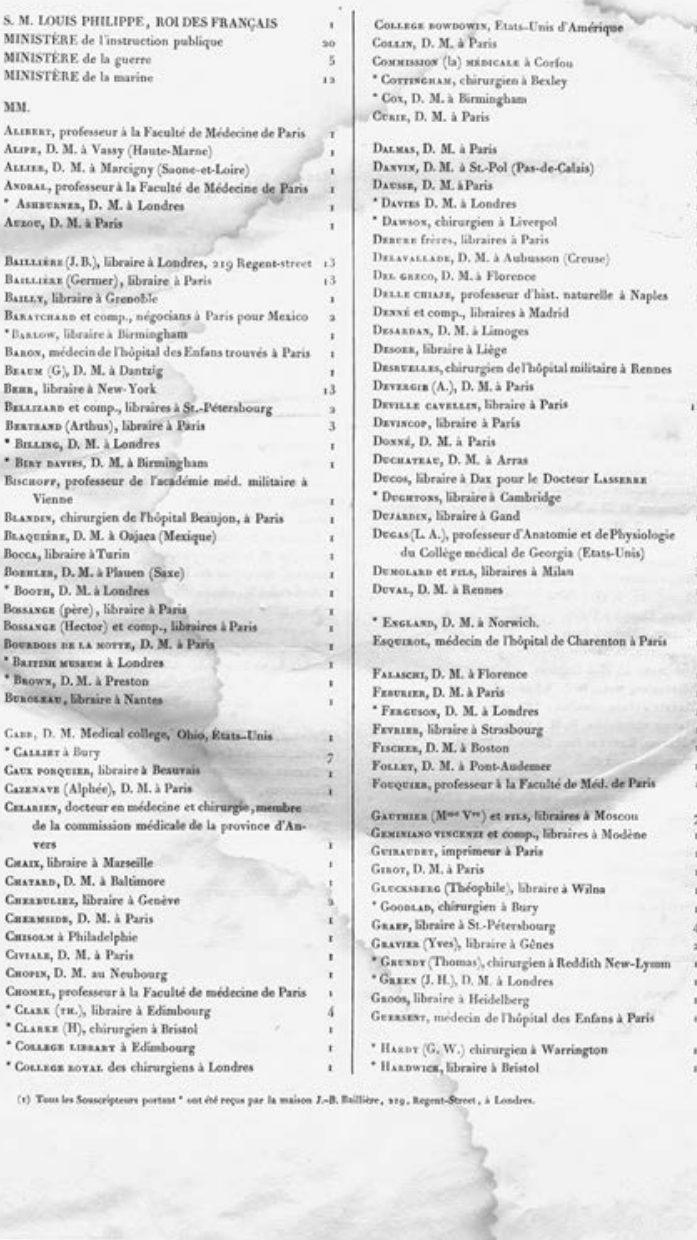

Figure 7. List of subscribers to Cruveilhier's atlas (page one of two). J. (Jean) Cruveilhier, Anatomie pathologique du corps humain: ou, Descriptions, avec figures lithographiées et coloriées, des diverses altérations morbides dont le corps humain est susceptible, I829-42, liste des souscripteurs. (Photo: Osler Library of the History of Medicine, McGill University). 
ranged from government ministries to eminent anatomy professors, college libraries, medical societies, and hospitals. The fact that the list included the names of professors from around the world (anatomists posted at Oxford, Glasgow, Moscow, Rome, Boston, and New York, for example) gave it even more authority. Clearly this was considered to be an authoritative and disciplined medical work of great interest to scientific readers, strongly endorsed by elite members of the scientific community. This listing of prestigious people and institutions, placed prominently on the second page of the atlas, obviously served as an ideal form of advertisement, and Chez J.B. Baillière must have known the privileging effect this strategy would have. Essentially, the function of this well-placed listing by the publisher was to align the work with notable physicians and, by metonymy, with the most prestigious medical communities of several countries; to the modern reader it offers valuable information about where these expensive and important rare books were sent.

Another destination for illustrated atlases produced during this period was presumably the private library of the gentlemanly patron or bibiliophile collector, who may or may not have been connected to the scientific field. Private gentlemen's libraries at the end of the eighteenth century often spanned a variety of topics, and were at the whims of the intellectual curiosity of the bibliophile, who often considered himself a natural philosopher of knowledge. ${ }^{34}$ It was not uncommon for nineteenth-century physicians to have collected a stock of medical books. For example, Baillie's collection was essentially a modern medical library -48 percent of the nine hundred printed books in the collection were published in the first twenty-three years of the nineteenth century. ${ }^{35}$ Arthur Farre, Professor at King's College and lecturer on comparative anatomy at St. Bartholomew's Hospital in the early decades of the nineteenth century, possessed about one

34 Paul Potter maintains in his study on eighteenth-century private medical libraries that as book enthusiasm grew and was nourished by the unparalleled increase of English wealth with its concomitant growth of "taste," the private library no longer served primarily an intellectual or scholarly function. Rather, it became what he refers to as a "collection" assembled for the delight and the spiritual elevation of the possessor and the visitor. See Paul Potter, "Taste Sets the Price: Mead, Askew and the Birth of Bibliomania in Eighteenth-Century England," Canadian Bulletin for Medical History / Bulletin canadien d'histoire de la médecine I2, no. 2 (I995): 24I-57.

35 Baillie bequeathed both his books to the Royal College of Physicians at his death. See Franco Crainz's The Life and Works of Matthew Baillie (I76I-I823) (Rome: Peliti Associati, 1995). 
thousand medical books covering various topics related to medicine from the seventeenth to early nineteenth century. It is not known if physicians like Baillie and Farre circulated the books from their private libraries, but some private libraries, like that of John Coakley Lettson, which contained about six thousand volumes, were open to medical professionals on Saturdays. ${ }^{36}$

To remedy medical schools' lack of access to books to some extent, medical book societies were developed during this period as a way for physicians to borrow each other's books. These book-circulating clubs, dating from 1770 , consisted of a few medical men banding together to purchase and circulate books, primarily among themselves. ${ }^{37}$ The Medical Reading Society of Bristol, for instance, was established in I807 with the specific purpose of "promoting medical knowledge and a friendly intercourse of its members, and for purchasing medical books." ${ }^{8}$ With the vast number of medical treatises and atlases being produced, these exclusive medical book societies were a means for established physicians to keep abreast of the literature as it developed; physicians could consult with one another on the desirable books and periodicals in the medical field as they were published. It was not until around the I840s, however, that public circulating libraries, clubs, and reading rooms were developed to circumvent the high prices of books such as the atlases. Until this time, anatomical atlases remained relatively inaccessible, as most people could not afford them.

\section{The Revised Smaller Anatomical Atlases and Textbooks, 1840s: Technological Changes, Shifting Commercial Strategies and the New Medical Student Markets in Medical Publishing}

In most cases, the initial oversized early-nineteenth-century atlases that incorporated coloured plates were not only very expensive, but also heavy and hard to handle. One physician argued against the format of the folio- and elephant-sized atlases, stating that "they are only suited for consultation at home; they cannot be carried into the

${ }_{36}$ See Thomas Pettigrew's Memoirs of the Life and Writings of the Late John Coakley Lettsom, with a Selection from his Correspondence (London: Nichols, I8I7).

37 See W.J. Bishop, "Medical Book Societies in England in the Eighteenth and Nineteenth Centuries," Bulletin of the Medical Library Association 45, no. 3 (1957): 337-50.

38 L.M. Griffiths, "The Medical Reading Society of Bristol," Bristol MedicoChirurgical Journal 25, no. 97 (1907): 222-35. 
anatomical theatre and the dissecting-room." 39 Moreover, their large size and weight made them difficult to read and arduous to use as a textbook. Readers often needed to piece together information that extended over a number of large and heavy volumes. For example, in the case of Cloquet's I825 edition, one needed to read across three thick volumes: one volume was the text explaining the structures, the second was the information related to the figures, and a third was reserved for illustrations. ${ }^{40}$ To comprehend the information the standard way, the reader needed all three books open at once to integrate information from the illustration, caption, and text. The amount of table space required to accommodate three open folios, as well as the physical strength required to haul around this triple decker, made using the multi-volume sets cumbersome. The expansive formats that most of the initial volumes of the atlases adhered to were thus impractical and frustrating to both medical students and physicians.

Both physicians and publishers recognized that the elaborate illustrated atlases produced in the first few decades of the century incurred high costs and yielded low sales. While there were some initial forays into cheaper editions in the early century, it was in the I840s that publishing firms began to make their medical textbooks available to a broader audience. Medical publishers began to alter their publishing strategies as a result of the convergence of a number of significant factors. These shifts in strategies changed how later editions were conceived, printed, circulated, and bound. To meet these ends, anatomical atlases were subjected to an expanding array of commercial demands, the new interests of publishers, authors, and medical students, as well as the new techniques offered by increasingly automated printing presses.

By the I840s, the book-printing industry was reaping the benefits of the steam technology introduced for newspaper publishing earlier in the century. A large amount of the hand labour previously required was reduced as a result of various mechanical developments. Printing was now done on large machines with longer print runs that could produce much greater quantities. ${ }^{4 \mathrm{I}}$ Stereotyping and mechanical

39 J. Masse, A Pocket Atlas of the Descriptive Anatomy of the Human Body (New York: Harper, I855), 33.

40 Jules Cloquet, Manuel d'anatomie descriptive du corps humain. Anatomie de l'homme, ou description et figures lithographiées de toutes les parties du corps humain (Paris: De l'Imprimerie de A. Belin, I82I-3I).

${ }^{4}$ A landmark in the mechanization of printing was the steam-powered press introduced by Friedrich Koenig. It boasted two cylinders capable of printing 
typecasting and typesetting continued to simplify the printing process and dramatically raise output. The new types of case bindings that emerged at this time also allowed for mass production and greatly streamlined the binding process. These simplified bindings could accommodate the use of arming presses and, later, steam presses to emboss covers with engraved metal dies, effectively replacing binders who used hand stamps and engraved metal rolls to impress cover designs and decorate books with gilt. As a result of the need for speed, simplicity, and economy, mechanical and mass production drastically changed how books were produced.

Technical changes in the printing industry developed alongside major changes in the ways that books were distributed. The changes in train service in Western Europe - to steam-powered locomotives - extended lines to all parts of the United Kingdom. This gave publishing firms access to a national market at low cost. At the same time, the Penny Post in England made ordering and payment quick and simple: requests to booksellers could be made directly to the publishing firm, or through brokers or agents. As a result of these changes in production, communication, and distribution, books could be distributed with greater ease and at cheaper rates. By the I840s, the book trade was expanding rapidly as a result of an unprecedented market for inexpensive books in all genres.

As publishing firms focused on securing profits, they recognized a new market - the growing medical student readership. Medical students were in need of pedagogical texts that would enrich and perpetuate the anatomical and clinical traditions currently being established in the private and hospital-based anatomy schools. A number of printing firms, like Churchill's, began to specialize in supplying students with their textbooks for courses at the London medical schools and selling them published lectures. These efforts to cater to the increased number of medical students by the middle of the century resulted in new types of pedagogical texts and new versions of anatomical atlases that made full use of the available technologies. The differences between the initial editions and these later volumes were immensely significant as a remarkable number of

both sides of a sheet simultaneously, and was capable of printing 750 sheets per hour (compared to I50 sheets per hour on a hand press). See John Tebbel, A History of Book Publishing in the United States (New York: R.R. Bowker, I972), 258. 
strategies were introduced around 1840 to drastically reduce the costs of anatomical atlases.

As atlases were reissued in a new format that was smaller and cheaper, large oversized folio- or elephant-sized volumes were replaced with less expensive quarto or octavo sizes. (See fig. 8.) The amount of information that appeared on each page of the revised editions was often considerably condensed owing to narrower margins, smallersized type, and closer line spacing. All of these changes meant that new and revised editions of the atlas could be printed cost-effectively and offered at a much cheaper rate.

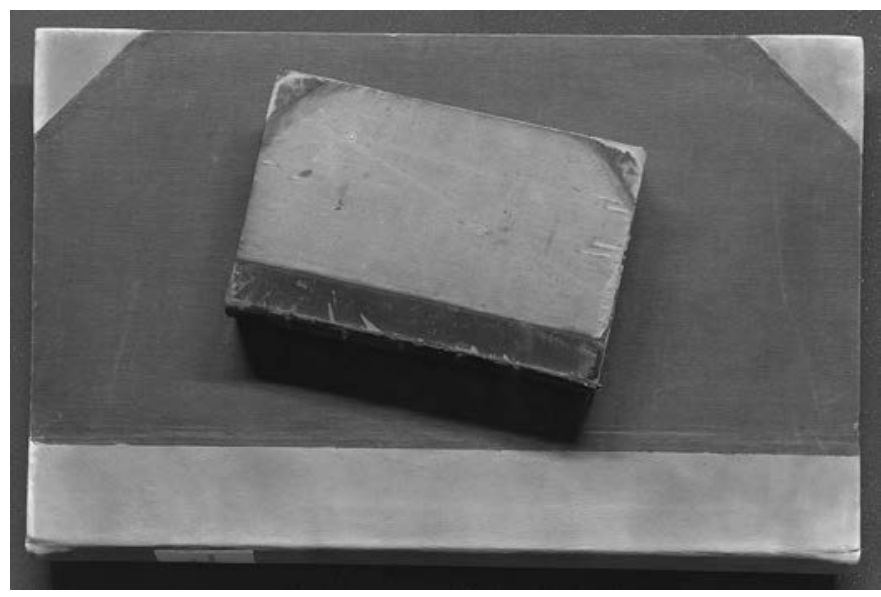

Figure 8. Comparison of Quain's elephant-sized folio with his hand-held atlas. Jones Quain, A Series of Anatomical Plates: with References and Physiological Comments Illustrating the Structure of the Different Parts of the Human Body / edited by Jones Quain and Erasmus Wilson, 1842; and Jones Quain, Elements of Anatomy / by Jones Quain; edited by Richard Quain and William Sharpey, sth ed., 1848. (Photo: Osler Library of the History of Medicine, McGill University).

One example of an anatomical atlas that was effectively reconceptualized to meet the various demands and interests of medical students was Jones Quain's volume, regarded during this period as the standard text used by every student of anatomy and physician in Europe for at least twenty years. Quain's initial volume, first published in I828, was a small and thick one-volume work, with no illustrations at all. ${ }^{42}$

42 It was among the most important of the English textbooks on anatomy. The initial volume was Elements of Descriptive and Practical Anatomy: for the Use of Students (London: W. Simpkin and R. Marshall, I828). 
Quain later joined forces with Erasmus Wilson to produce an array of elaborate large plates, sold separately, either in plain black and white, or (for guineas more) hand coloured, issued in fascicle over several years. ${ }^{43}$ According to an I834 review in the Medical Quarterly, this atlas was to consist of 125 fascicles in total, with two fascicles to be published every month. ${ }^{44}$ When the project was completed and bound, it consisted of two weighty folio volumes totaling I,36I pages. These elaborate volumes were priced accordingly: £I2 was the initial offering price for black and white and $£_{20}$ for colour. ${ }^{45}$ Most medical students could not afford the full set of fascicles when they were advertised or as they were published, nor could they afford or manage to assemble it: plates got lost, and even bound copies were often incomplete. Many editions of Quain's atlas followed, because of its popularity. ${ }^{46}$ However, to maintain this popularity, the atlas underwent a major shift in the I848 edition. Quain's brother Richard Quain, who eventually became a professor of descriptive anatomy and clinical surgery at University College Medical School in London, edited this fifth edition of his brother's atlas, offering new materials, adding to his brother's original treatise while retaining its title. However, the atlas changed to a smaller size and format, bound in two volumes, with all illustrations in black and white only, rather than in colour. (See fig. 9.) This I848 edition of Quain's atlas was offered at the more reasonable price of twenty shillings, $£_{2}$ for the two volumes. ${ }^{47}$

43 Jones Quain and Erasmus Wilson, A Series of Anatomical Plates: With References and Physiological Comments Illustrating the Structure of the Different Parts of the Human Body (London: Printed for Taylor and Walton, by Samuel Bentley, I842).

44 See advertisement in Medical Quarterly Review 2 (I January I834): 374.

45 By 1848 , the price of a complete set of Quain and Wilson's illustrated textbook was already reduced, and advertisements noted that booksellers were selling "cheap issues" of the two-volume, royal folio set with gilt tops and half-bound morocco leather for greatly reduced prices of $£ 8,8$ shilling, or $£$ I 4 coloured. See Publisher's Circular (I January I848): I2.

46 The eleventh edition was published between 1908 and 1929 and had several distinguished editors and contributors. Edward Albert Schäfer, Johnson Symington, Thomas Hastie Bryce, eds., Quain's Elements of Anatomy, IIth ed. (London and New York: Longmans, Green, and Co., 1908-29).

47 Jones Quain, Elements of Anatomy / by Jones Quain; edited by Richard Quain and William Sharpey, 5th ed. (London: Taylor, Walton, and Maberly, I848). It is notable that Richard Quain was also the author of his own highly regarded atlas, The Anatomy of the Arteries of the Human Body: With its Applications to Pathology 


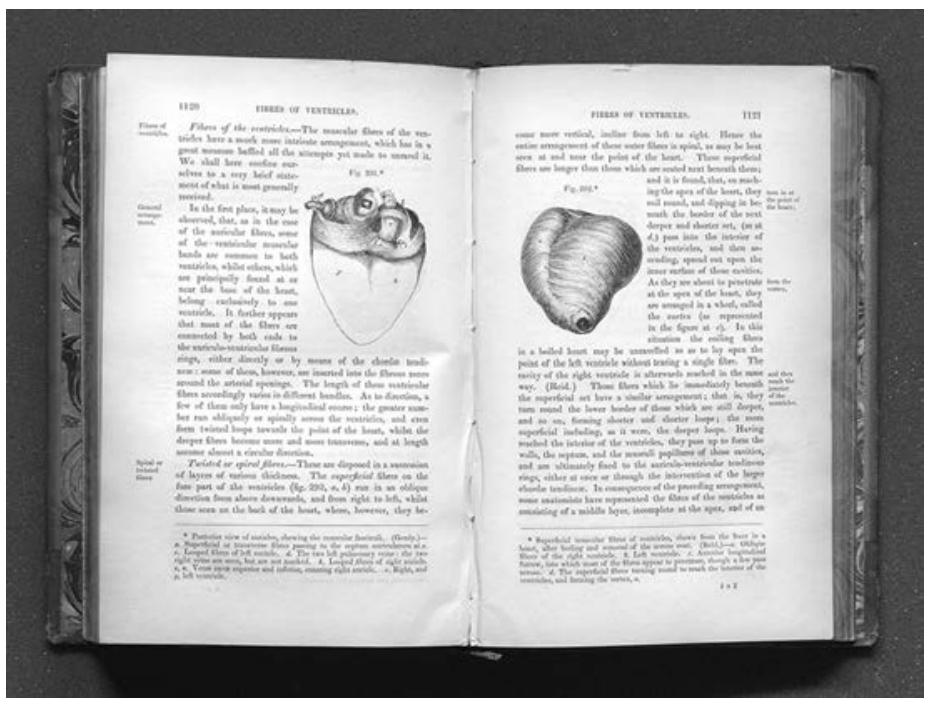

Figure 9. Jones Quain, Elements of Anatomy / by Jones Quain; edited by Richard Quain and William Sharpey, sth ed., I848. (Photo: Osler Library of the History of Medicine, McGill University).

The circulation and distribution of these later revised editions was markedly different than for the expensive atlases produced in the I820s and I83os. Medical students and average physicians could now, for the first time, own personal copies of anatomical atlases. Atlases were no longer the preserve of bibliophile collectors and elite physicians. These later editions of atlases were produced in much greater numbers owing to the lowered production costs, and they were circulated much more easily and effectively.

\section{Conclusion}

This article has explored how illustrated atlases circulated widely as the tools of a new technique of power at the turn of the nineteenth century. It has argued that the anatomical atlas was a series of commercialized and discursive texts constantly reconceptualized during the first half of the nineteenth century to meet the various demands, interests, and desires of potential buyers.

and Operative Surgery. In Lithographic Drawings, With Practical Commentaries ... The Delineations ... / by Joseph Maclise (London: Taylor \& Walton, I84I-44). 
The anatomical atlas functioned to support the changing professional status of the physician. At the same time as physicians became more entrepreneurial, competing for positions and for students, they also began to identify as scientists. Throughout the nineteenth century, elite medicine was a field where disputes were waged over priority of discovery. The possession of a great scientific discovery was of direct advantage in a competitive context. Anatomical atlases were one of the dominant sites for this new entrepreneurial identity of the scientific physician. Clearly, these factors were at stake when elaborate and expensive formats were chosen for "emblematic" atlases. The meticulously rendered folio format was reserved for medical heroes who embodied values and aspirations that the atlases served to validate in the medical community.

Economic rationality and market-driven behaviour became the norm during the nineteenth century, and this affected medicine no less than other spheres of culture. Market incentives in the book trade directly influenced the development of the anatomical atlas. This article has shown how new sets of needs and expectations from middle-class clients, medical students, and circulating libraries, for instance, resulted in major changes in the printing, circulation, and binding of atlases. An interesting aspect of such entrepreneurship in the book trade was that the search for competitive advantage around the middle of the century led to new technological innovations, such as steam-powered presses, new printing techniques, and simultaneous printing of text and images. In this regard, these new types of teaching atlases were the result of the adoption of the latest innovations in printing and formatting techniques. These experimental initiatives led to more serviceable pedagogical atlases.

The profusely illustrated anatomical atlas clearly worked to establish the efforts of the physician as professional, authoritative, and disciplined scientific works. They also functioned as a commodity for both medical knowledge and in the markets for books. There was a constant collision between the requirements of scientific discovery and teaching, on the one hand, and the constraints of contemporary publishing, on the other hand. The various techniques and systematizing formats of publishing as it developed throughout the first half of the century imposed discipline on the ways that medical illustrations and medical discourse appeared and were produced. At the same time, medicine's new anatomical approaches demanded newly reordered types of anatomical textbooks. The alignment of anatomical illustration rooted in dissection resulted in varying atlas 
formats, publishing strategies, and technical developments over the course of the first half of the nineteenth century. This meant that medical knowledge gained a multiplicity of complex new meanings as physicians began to establish visual genres as dominant modes of knowledge at the beginning of the century and sought to construct a new normative knowledge of the body. ${ }^{4}$

\section{RÉSUMÉ}

Dans cet article, l'auteure se penche sur le développement des atlas du corps humain, des imprimés illustrés qui ont évolué au dix-neuvième siècle en fonction des changements qui bouleversaient alors le champ de la médecine. Au cours de ce siècle, ces atlas se déclinaient sous divers aspects, formats et structures et s'adressaient à différents lectorats. Tant les éditeurs commerciaux que les innovations au sein de l'industrie du livre elle-même ont considérablement influencé ces grands in-folio, lesquels intéressaient surtout - du moins, dans un premier temps - les clients fortunés. Cependant, vers le milieu du dix-neuvième siècle, des usages pédagogiques inédits de ce type d'atlas ont peu à peu fait leur apparition. Â cette époque, les nouvelles technologies, les stratégies éditoriales ainsi que les exigences liées à l'enseignement ont grandement influencé la production et la circulation du savoir médical.

$48 \quad$ I would like to thank Christopher Lyons, Head Librarian at the Osler Library of the History of Medicine, for his kind support of my research and intellectual endeavours over the past decade. In addition I thank the anonymous reviewer and editors whose comments improved this article. I am also grateful to Lily Szczygiel from the Osler Library for the History of Medicine who worked on the images for this article, as well as paper conservator, Jonathan Browns, who provided early and enthusiastic feedback. 